\title{
A patologia da representação: participação social e representatividade no Conselho Municipal de Saúde de Rio Branco/Acre
}

\author{
The pathology of representation: social participation and representativeness in the municipal \\ council of health of Rio Branco/Acre
}

La patología de la representación: participación social y representatividad en el Consejo Municipal de Salud de Rio Branco/Acre

\section{Resumo}

Esta pesquisa objetivou a compreensão da forma como a participação social se desenvolve no Conselho Municipal de Saúde, do município de Rio Branco/Acre-Brasil. Foi utilizada uma abordagem qualitativa e a metodologia de estudo de caso. A investigação foi realizada em etapas, sendo elas: acompanhamento das reuniões do referido órgão, com a utilização da técnica conhecida como observação sistemática; a segunda consistiu na análise documental das atas das reuniões e documentos gerenciais; e, realização de entrevistas com todos os conselheiros. Este conselho apresentou como entraves a sua efetivação e real democratização da gestão das políticas públicas de saúde, os seguintes obstáculos: relações assimétricas de poder; dificuldades de representação, principalmente no segmento dos usuários; falta de capacitação para o pleno exercício do mandato de conselheiro. Existe um potencial de compartilhamento de poder e responsabilidades, em espaços como estes, e os atores envolvidos devem ter o seu esforço de participar valorizado e incentivado, dando-lhes voz e escuta e tendo suas intervenções e, ou solicitações atendidas.

Palavras-chave: Conselho de saúde; Participação social; Democracia.

\begin{abstract}
This research aimed to understand how social participation is developed in the Municipal Health Council, in the city of Rio Branco/Acre-Brasil. A qualitative approach and case study methodology were used. The investigation was carried out in stages, namely: monitoring of the meetings of that body, using the technique known as systematic observation; the second consisted of document analysis of the minutes of the meetings and management documents; and, conducting interviews with all counselors. This council presented the following obstacles to its implementation and real democratization of the management of public health policies as obstacles: asymmetrical power relations; representation difficulties, especially in the user segment; lack of training for the full exercise of the mandate of a councillor. There is a potential for sharing power and responsibilities in spaces like these, and the actors involved must have their effort to participate valued and encouraged, giving them a voice and listening and having their interventions and/or requests met. Keywords: Health council; Social participation; Democracy.
\end{abstract}

\section{Resumen}

Esta investigación tuvo como objetivo comprender cómo se desarrolla la participación social en el Consejo Municipal de Salud, en la ciudad de Rio Branco / Acre-Brasil. Se utilizó un enfoque cualitativo y una metodología de estudio de casos. La investigación se llevó a cabo por etapas, a saber: seguimiento de las reuniones del mencionado organismo, utilizando la técnica conocida como observación sistemática; el segundo consistió en el análisis documental de las actas 
de las reuniones y documentos de gestión; y realizar entrevistas con todos los consejeros. Este consejo presentó como obstáculos para su implementación y democratización real de la gestión de las políticas públicas de salud, los siguientes obstáculos: relaciones de poder asimétricas; dificultades de representación, especialmente en el segmento de usuarios; Falta de formación para el pleno ejercicio del mandato de concejal. Existe potencial para compartir poder y responsabilidades en espacios como estos, y los actores involucrados deben tener su esfuerzo de participación valorado y alentado, dándoles voz y escucha y cumpliendo sus intervenciones y/o solicitudes.

Palabras clave: Consejo de salud; Participación social; Democracia.

\section{Introdução}

A necessidade do envolvimento da sociedade nas questões que norteiam a saúde tem sido sentida em vários países. Apesar de, a participação social no Brasil ser uma prerrogativa legal, ainda são enfrentados entraves à sua efetivação. Este artigo se propõe a compreender como esse processo de participação social se dá no ambiente do Conselho Municipal de Saúde de Rio Branco. Foi utilizado o aporte teórico da democracia. Autores defendem que, a democracia assumiu um papel central no campo político atual (Santos, Avritzer, 2002). Os estudiosos apontam uma diferenciação entre os modelos de democracia adotados. Sendo eles; democracia representativa, participativa e deliberativa, este último proposto por Habermas (1996). Os modelos baseados apenas na representação têm sido cada vez mais questionados. Tendo em vista que restringe as formas de participação a um procedimento eleitoral, influenciam pouco na qualidade de vida das pessoas, além disso, os grupos mais vulneráveis têm dificuldades de ter seus interesses defendidos em igualdade de condições com os grupos economicamente mais prósperos e numerosos (Sader, 2002). A democracia participativa tem sido apresentada como alternativa à questão democrática. As experiências políticas denominadas democracia participativa, são de afirmação de direitos sociais, os quais, embora existentes formalmente, na prática não são assegurados. Tais iniciativas tendem a resgatar a dimensão pública e cidadã da política.

Outra discussão que contorna os fundamentos teóricos da democracia, e que está atrelada à democracia participativa é a deliberação. A democracia deliberativa foca no processo comunicativo de expressão e formação de opiniões que precede a votação. Tem o consenso como o conceitual núcleo de legitimidade. Esta legitimidade é obtida através de algo que é publicamente articulado, explicado e, mais importante ainda, justificado como política pública (Habermas, 1996). Habermas (1996) defende o uso da negociação como uma peça central da política deliberativa, que consiste em uma rede de discurso e o processo que é posto para facilitar a solução racional de questões pragmáticas, éticas e morais. Reforça ainda que sempre, sob condições ideais, discurso e negociação podem desenvolver solução para os problemas, mas somente quando os problemas são sensivelmente percebidos, adequadamente descritos e produtivamente respondidos à luz de uma reflexiva, pós-tradicional transmissão de cultura.

Neste estudo, adotou-se o termo participação social, para caracterizar ações ou processos de democracia participativa. A importância da participação social é defendida por vários autores (Pateman, 2012; Santos, 2002; Krüger e Serapioni, 2020; Bispo-júnior e Serapioni, 2021), mas, essa participação deve ser qualificada e politizada, deve ainda haver o empoderamento de categorias mais excluídas e vulneráveis da sociedade. Para isso, faz-se necessário, além da educação, da informação, o direito de voz, das pessoas e das comunidades, no planejamento e na execução das políticas públicas.

Apesar da existência de todo um aparato legal para a obrigatoriedade da existência de espaços institucionais de participação, que são os Conselhos de Políticas Públicas, há uma discussão sobre sua real efetividade. Sabe-se que a simples existência dos conselhos não garante a participação da sociedade.

\section{Metodologia}

Esta pesquisa foi realizada adotando-se uma abordagem qualitativa. Sendo um estudo de caso, da participação social, no Conselho Municipal de Saúde do município de Rio Branco. A pesquisa foi realizada em etapas, a primeira delas consistiu no acompanhamento das reuniões do referido órgão, a fim de se conhecer e familiarizar com as diversas entidades e órgãos 
governamentais e não governamentais representados na instituição colegiada, assim como a identificação dos representantes dos usuários do sistema de saúde e conhecimento da política pública de saúde apresentada pelo gestor aos conselheiros e pautas de discussão.

Esta primeira etapa da pesquisa durou 12 meses, no período compreendido entre Outubro de 2011 a outubro de 2012. Paralelamente, foram realizadas as entrevistas e pesquisa documental. Durante o acompanhamento e observação das reuniões do colegiado do CMS, foi adotada uma técnica para a observação das mesmas, conhecida como observação sistemática. No caso desse trabalho, a observação sistemática foi realizada com roteiro e com uma definição anterior dos espaços. As observações foram registradas através de anotações em diário de campo, e posteriormente analisadas, juntamente com as outras informações levantadas com as demais técnicas utilizadas neste trabalho.

A segunda etapa consistiu na busca de fontes documentais, a fim de identificar propostas e ações ou políticas resultantes das deliberações do CMS de Rio Branco. Assim, nesta pesquisa, nos propusemos a analisar os documentos de planejamento e gestão da Secretaria Municipal de Saúde, relatório da Conferência Municipal de Saúde (ano de 2011), bem como as atas das reuniões do CMS, por um período de quatro anos, compreendidos entre 2008 e 2011. Diante da vasta gama de informações contidas nestes documentos, selecionamos informações de registros de participação social, na formulação de políticas públicas. Identificamos, assim, propostas das Conferências Municipais de Saúde, que realmente tenham tido a participação da sociedade e que se transformaram em ações executadas pelo poder público, através dos planos e metas contidos nos planos de saúde e apresentados à sociedade através dos respectivos relatórios de gestão. Também se buscou a identificação dos processos de participação da sociedade no órgão colegiado, através do registro das reuniões nas atas do CMS.

$\mathrm{Na}$ terceira e última etapa da pesquisa de campo, foram realizadas entrevistas com atores sociais, eleitos a partir da primeira etapa. Tais entrevistas objetivaram a elucidação de algumas das questões que permeiam as relações no ambiente interno dos órgãos colegiados, tais como:

-Entendimento ou percepção de relações de poder dentro das instâncias colegiadas;

-Nível de comunicação entre representantes e seus pares de entidades originárias;

-Grau de conhecimento dos componentes sobre políticas públicas de saúde e da máquina administrativa da secretaria municipal de saúde;

-Nível de compromisso da entidade gestora com o órgão colegiado;

-Entendimento ou percepção da importância do papel de representante (no caso dos usuários) e auto-estima;

-Resolubilidade de acordo com as demandas dos representantes da sociedade civil.

Foi possível entrevistar 15 dos 16 conselheiros, priorizamos entrevistar os membros titulares. Para a realização das entrevistas, utilizamos um roteiro de questões norteadoras, apenas com a finalidade de direcionar o diálogo de modo que atendesse aos propósitos desta pesquisa, sendo que os entrevistados ficaram livres para falar e expressar suas concepções sobre o assunto em questão, seguindo as orientações de Gil (2019), a respeito da entrevista semiestruturada. Estas entrevistas foram gravadas e posteriormente transcritas com fidelidade para análise, esta foi realizada utilização da técnica de análise de conteúdo (Chizzotti, 2005). Turato (2008) defende que esta aplicação necessita de complementação, aconselha ainda, que todos os que utilizam as diversas modalidades da técnica de análise de conteúdo que avancem para além do estágio meramente descritivo, para que se possa permitir a discussão partir dos dados trabalhados.

O projeto foi aprovado pelo Comitê de Ética em Pesquisa da Faculdade de Saúde Pública da Universidade de São Paulo, pelo of. COEP/268/11. Esta pesquisa é um subproduto de uma tese de doutoramento em Ciências pela Faculdade de Saúde Pública da Universidade de São Paulo. 


\section{Resultados e Discussão}

Dos quinze conselheiros entrevistados, oito estavam no segundo mandato deste conselho. Também oito participam ou já participaram de outros conselhos de políticas públicas. Sobre a participação em capacitação para formação de conselheiros, apenas quatro haviam participado. Com relação ao critério de escolha para a representatividade dos conselheiros pelas entidades, todos afirmaram que foram indicados, alguns devido à disponibilidade de tempo e interesse ou afinidade com a política do conselho. A maioria tem envolvimento com movimentos sociais.

\section{A dinâmica e o funcionamento do conselho}

Da observação das reuniões do conselho foi possível, além de conhecer a rotina do conselho, identificar os assuntos que são trazidos a ele com frequência. Constatou-se que, a grande maioria dos pontos de pauta discutidos em plenário era encaminhada pela Secretaria Municipal de Saúde. Muito raramente acontecia de algum conselheiro trazer algo para ser debatido, quando ocorria, eram geralmente queixas de um ou outro serviço oferecido pela secretaria. A pauta de uma reunião é composta pelos assuntos que serão deliberados. Assim, a sua construção indica a capacidade de os atores envolvidos intervirem no processo decisório. Se uma pauta é construída coletivamente, prediz o grau de democratização dessa instituição, sendo que mais pessoas estão envolvidas nesse processo. Ao contrário, uma pauta elaborada apenas pela presidência, ou pior, como neste caso, pelo segmento do governo, indica um grau de democratização ou participação mais baixo.

Outro aspecto observado na dinâmica de funcionamento foi que, aqueles que tinham uma postura mais ativa e crítica, frente ao que era exposto, eram aqueles que já tinham histórico de envolvimento em movimentos sociais, geralmente presidentes de entidades. Verificou-se, assim, uma heterogeneidade em relação às posturas dos conselheiros, umas mais pró-ativas e outras mais retraídas, estas últimas limitando-se apenas a aprovar ou não o que era apresentado.

A maioria dos que tinham um posicionamento mais passivo eram os representantes das categorias profissionais e prestadores de serviços. Este fato foi algo que surpreendeu, pois se achava que, por ser o profissional de saúde um “conhecedor de causa", ou seja, tem ou se espera que tenha um maior domínio das questões tratadas naquele fórum, fosse mais atuante, inclusive influenciando o processo de tomada de decisão, porém, no caso específico deste conselho, isso não ocorreu. Geralmente, o ambiente das reuniões era de cordialidade, exceto em algumas poucas ocasiões pontuais. Normalmente, os conselheiros tendiam a aceitar sem muitos questionamentos o que estava sendo proposto. Quando eles foram indagados, em entrevista, sobre essa questão, um até afirmou: “Esse pessoal que está ai é muito bom [...], é difícil você ir contra uma coisa que já é boa". O que colaborava para o clima harmonioso no plenário do conselho, era que a maioria dos conselheiros tinha a mesma identidade partidária que o secretário e consequentemente o prefeito. Ainda sobre esse aspecto, havia no ambiente do conselho uma articulação partidária semelhante às articulações nas instâncias legislativas. Expondo, desse modo, fragilidade e despreparo em lidar com a pluralidade partidária que deveria existir em espaços como este. Que neste caso não foi observada, ao contrário, a maioria dos conselheiros se portavam como adeptos do partido em questão, se houvesse alguma ideologia contrária não era manifesta, até para não se romper com a aparente "harmonia" do plenário.

Outra questão relevante e, inclusive mencionada no conselho, por um convidado, foi a questão de que o controle social deveria ser exercido por entidades que não tivessem vínculo com o poder público, através de convênios. Nesse aspecto, a própria presidente do conselho saiu em defesa da estrutura vigente, afirmando que no nosso Estado, não haveria instituições aptas, somente pessoas, visto que todas, ou quase todas, as entidades recebem algum tipo de auxílio do poder público. Sobre esse assunto, outro conselheiro falou sobre a crise de entidades, informando que a maioria dos conselhos, segundo ele, é o gestor quem indica quem são os conselheiros, prejudicando um debate mais amplo. Defendeu, ainda, que estes conselheiros já vêm com o discurso pronto e não têm preparo. De fato, a maioria das entidades que compõem o conselho no segmento dos usuários, mantém algum tipo de convênio ou parceria com o poder público, apesar de, as entidades manterem vínculos com instâncias 
estaduais, vale ressaltar que o estado e o município eram geridos pela mesma sigla partidária, e por isso, há uma relação de cordialidade mediada pelo grau de cumplicidade política. Este fato também ficou evidenciado no estudo de Klein (2010), ao abordar o Conselho Estadual de Saúde do Acre. O mesmo era composto por 12 entidades no segmento dos usuários, destas, sete eram parceiras da Secretaria Estadual de Saúde, com convênios para a liberação de recursos financeiros.

Outra questão identificada no acompanhamento das reuniões deste colegiado foi que, em razão da necessidade burocrática de aprovação pelos conselhos gestores de projetos e políticas públicas, isso os torna, em alguns casos, meramente consultivos, sem uma construção coletiva do projeto, ou mesmo o envolvimento do conselho em uma etapa anterior de elaboração de propostas. Os conselheiros queixaram desse aspecto, quando um deles disse que era obrigado a dizer "sim ou não". Martinez e Kohler (2016) relatam também este achado, afirmando que o governo não compartilha o poder de decisão, limitando a capacidade do conselho de monitorar efetivamente o setor da saúde e de influenciar na formulação de políticas.

Em relação à prestação de contas, que é uma das principais atribuições dos conselhos de políticas públicas, observouse que por ser o orçamento um instrumento de gestão técnico, contábil, e os conselheiros, em sua maioria não tem conhecimentos suficientes para questionar, a prestação era analisada por uma comissão de cinco pessoas, sendo que apenas uma era representante do segmento dos usuários, e os demais funcionários da Secretaria Municipal de Saúde, incluindo o Secretário Municipal de Saúde. Tal comissão elaborava um parecer que era aprovado sem nenhum questionamento, mesmo sem informações precisas do tipo, quanto se gastou, em que área, dentre outros detalhes. Foi observado que havia muitas questões do âmbito da gestão que não são discutidas com o conselho, muitas decisões tomadas e apenas informadas, outras encaminhadas ao plenário do conselho, apenas para homologação. Observou-se uma postura defensiva da gestão, sempre que era questionada sobre a metodologia de tomada de decisão, sem o envolvimento dos interessados na questão, isso demonstra o quanto o gerenciamento dos serviços de saúde, está distante do propósito de uma gestão participativa e inclusiva. Outro aspecto também observado foi o fato de que o plenário do conselho teve, em alguns casos ou na maioria, tendência a se posicionar favoravelmente à gestão. Consequentemente, essa fragilidade do plenário torna possível a manipulação dos interesses dos representantes do governo.

\section{Achados documentais}

A análise documental confirmou o que já havia sido observado, muito do que era realizado no conselho, era mais para cumprir uma exigência normativa, portanto, insuficiente para garantir uma real participação social, tanto das conferências quanto das reuniões registradas em ata. As poucas propostas apresentadas, tanto nas conferências como nos planos de gestão, sobre a questão do estímulo ou fortalecimento da participação social, eram tímidas e evasivas, por exemplo: “[...] Identificar com o apoio do Estado às necessidades da população do seu território, fazer um reconhecimento das iniquidades, oportunidades e recursos", além de trechos como: "Realizar o planejamento participativo com a comunidade [...]. Apesar da menção à participação social, não foi explicitado, nos documentos, como será feito esse planejamento participativo, que estratégias serão tomadas para envolver a população nesse processo. Até o término dessa pesquisa, não houve mobilização do conselho ou da gestão nesse sentido. Outro compromisso também assumido, nos referidos documentos, foi garantir a autogestão financeira do conselho. A dependência financeira da secretaria compromete a autonomia do conselho, pois, todas as suas demandas financeiras são submetidas à secretaria, ficando assim seu atendimento ou não a cargo da sensibilização do gestor. Essa idealizada autogestão financeira também não ocorreu, até o término deste estudo.

\section{Entrevistas}

A partir do conteúdo das entrevistas, foram selecionadas quatro categorias analíticas, as quais são apresentadas e discutidas a seguir. 


\section{1) Representatividade}

Todos os conselheiros foram indicados pelas suas entidades, sejam elas governamentais, de categorias profissionais ou de usuários do sistema. Quanto a esse critério, não houve distinção entre os segmentos. Este também foi um achado de outros estudos (Cotta e Cazal, 2010; Almeida, 2010). A ausência de uma eleição para a escolha desse representante, no interior das entidades, retrata além de uma forma não democrática de escolha, pouco interesse dos membros em participar de conselhos de políticas públicas, sendo que não há muitos interessados em ocupar tal espaço, para que seja necessária uma votação. Conforme relata um trecho de uma entrevista, de um conselheiro representante do segmento dos usuários:

"Não, não há necessidade disso, (eleição) para ocupar os espaços, não. Por que cada um já tem uma área específica". Conselheiro- usuáriol.

"Sim, fui indicado [...] por eu já estar a bastante tempo no projeto e por eu ter disponibilidade de tempo também, daí eu fui indicado." Conselheiro-usuário2.

Há que se questionar a efetividade da participação, uma vez que, se não é possível garantir mecanismos eficazes de representação. Serapioni e Matos (2013), ao se reportarem sobre a questão da representatividade nos mecanismos participativos, caracterizam-no como um aspecto problemático dos processos deliberativos:

“[...] no caso da participação pública não se pode falar de participação de todos e a toda hora e a representatividade no sentido próprio do termo não existe, na medida em que não existem mecanismos formais de delegação através dos quais, grupos ou categorias de utentes possam escolher seus representantes" (pg.16).

Outra situação que emergiu entre as falas foi a ocupação dos espaços do conselho "cadeiras" para, de certa forma, fortalecer a entidade. É possível que haja legitimidade nesta busca, entretanto, observou-se que o segmento do usuário, que deve ser representado pelo conjunto das entidades, não é representado adequadamente, em detrimento de questões que envolvem situações específicas de cada entidade. Nesse aspecto, notou-se certo corporativismo. Conforme as falas:

“Antes, até 2008, não tínhamos participação em nenhum conselho de política pública [...] começamos a despertar o interesse para essa participação. Porque, tem um lema da gente, que fala o seguinte: quem não é visto, não é lembrado." Conselheiro-usuário 3.

“[...] Mas a (coordenadora) diz: "não, o (entidade) não pode perder a cadeira lá". Conselheiro-usuário 4

Há, também, o reconhecimento dos conselheiros de que os usuários não estão sendo representados no conselho como deveriam. Os entrevistados identificam os obstáculos para essa representação, afirmando o limitado alcance de suas ações, intervenções. Devido a isso, alguns conselheiros se detêm a tentar atender as expectativas ao menos de suas entidades.

"Ai chega um ponto que o conselheiro ele se limita muito a atividade associativa dentro do conselho [...] que você tem dificuldade de ver atendido naquela área de atuação, imagina estender um pouco mais para ter um horizonte mais amplo." Conselheiro-usuário2.

Esta fragilidade reforça o sentimento de impotência dos conselheiros diante do que consideram seus representados, influenciando negativamente na avaliação de eficácia dos conselhos, sendo que, tal situação contribui para a auto- estima baixa 
dos conselheiros e para o descrédito de suas ações. Outra limitação identificada foi o relacionamento com a entidade. Quando questionados sobre a rotina de participação, se havia discussão entre os pares sobre a pauta a ser tratada nas reuniões do conselho, ou, se após a reunião, havia retorno para as entidades sobre o resultado da deliberação, a maioria respondeu que não discutiam a pauta previamente com suas entidades, salvo em condições muito específicas, que de algum modo diziam respeito à entidade representada por eles. Quanto ao retorno, a maioria afirmou que repassavam como informes nas reuniões rotineiras das instituições. Outros afirmaram que só repassavam quando era algo que de alguma forma interessava ou envolvia a entidade.

"Não, eu realmente não tenho esse posicionamento, de trazer o que foi discutido lá, de dar o feed-back para a instituição. Alguns informes que é importante eu passar para os colegas, a gente acaba comunicando como cursos, etc, nesse sentido, mas de demanda do conselho pra cá não". Conselheiro-gestão1

Como já foi exposto, o usuário de modo geral não está sendo representado em sua essência, mas, e as entidades? Estão sendo representadas? Ou as vozes, os posicionamentos adotados são fruto de pensamentos, conclusões individuais dos conselheiros, baseados em suas experiências, perspectivas e impressões, já que não estão conseguindo, de algum modo, trazer o posicionamento das entidades para as discussões, decisões do órgão colegiado. Este fato contribui para fragilizar o plenário e torná-lo susceptível a manipulações ou influências de alguns atores que, por força do cargo/função ou poder de oratória, devido a um conhecimento privilegiado, conseguem conduzir o posicionamento dos conselheiros a um resultado favorável às suas propostas, sem que se trate realmente de uma decisão autônoma que corresponda à vontade ou necessidade da sociedade.

Outro achado, ainda relacionado à representatividade diz respeito aos custos da participação. Sabe-se que o envolvimento em atividades, em órgãos colegiados, não ocorre sem que haja necessidade de investimentos, sejam eles de: tempo, dinheiro, disposição, entre outros. Este é um fator que deve ser considerado, pois em entrevista, alguns conselheiros até afirmaram que foram escolhidos porque tinham tal disponibilidade e interesse, além de que estariam dispostos a dispensar esses recursos em prol do exercício da participação. Na verdade, esta atividade é vista por alguns membros do conselho como um fardo, um sacrifício que fazem em prol da visibilidade de sua entidade.

"Então é muito complicado, ou eu me dedico ao conselho, ou me dedico ao... (instituição). Não que eu não goste de tá no conselho, é legal". Conselheiro-usuário4

"É, tipo na reunião passada, eu tinha que ir para lá, e a minha gerencia, não entendeu, ou não sabia, e eu levei uma falta, e ai isso compromete a minha vida". Conselheiro-trabalhador1.

A construção da cidadania não é livre de ônus, pelo contrário, há, na problemática da participação, uma série de compromissos e investimentos que são exigidos dos envolvidos.

\section{2) Conhecimento/capacitação/formação/experiência}

Outra categoria, que emergiu na análise das entrevistas, foi a questão do conhecimento e necessidade de capacitação dos conselheiros. Esta problemática foi levantada até mesmo entre os representantes dos profissionais, prestadores de serviços e instituições de ensino. Entre as falas, surgiram, desde percepções de que os conselheiros devem ser "quase especialistas", até posicionamentos de que devem ter mais representantes dos grupos mais excluídos ou vulneráveis da sociedade. Todos os entrevistados deram ênfase a esta questão, até mesmo o secretário de saúde.

Questionamos em entrevista aos conselheiros se eles tinham conhecimento/familiaridade com os assuntos/ questões que são levantados no plenário do conselho, ao que nos responderam: 
"Fica limitado, por que muitas vezes são usados termos técnicos e algumas vezes não usam termos técnicos, mas de familiaridade de quem atua na área de saúde, especificamente por funcionários da área da saúde, eu particularmente, até outros conselheiros que não tem atuação na área de saúde tem dificuldade de compreensão". Conselheiro-usuário2. “... tem assuntos, que fico voando”. Conselheiro-trabalhador2.

Sabe-se que, seria impossível que todos dominassem todos os assuntos tratados naquele fórum de discussão, especialmente por se tratar de um grupo muito heterogêneo. O que é um fator positivo. O problema que se identifica neste achado da pesquisa é a atitude frente a esse obstáculo, que se coloca a uma efetiva participação e deliberação. Quando questionado aos conselheiros qual a atitude tomada por eles nestas situações, apesar de alguns revelarem pró-atividade, informando que questionam, debatem, tentam esclarecer suas dúvidas, a maioria respondeu que se omite, não questionando aos preletores.

“... mas ai, acaba que a gente fica calado. Diz: "Ah, eu não vou nem discutir, nem questionar”, por que alguma vez você pergunta: o que é isso? Do que se trata, mas outras, você acaba deixando passar, por que há tantos questionamentos, por que você acaba passando vergonha, de tanto questionar, entendeu? Conselheiro-trabalhadorl

O temor do constrangimento impede alguns conselheiros de se manifestarem, pedir esclarecimentos. Esse posicionamento pode comprometer o processo decisório. Também questionamos aos entrevistados qual a atitude percebida dos colegas. A maioria respondeu que percebem timidez e omissão:

"No geral, o silêncio. Isso é a maioria, geralmente tem esse comportamento, de se encolher ou ter vergonha de perguntar. Infelizmente é isso que acontece, a pessoa não sabe, e não se abstêm. Infelizmente, atitude é aquela, ou você se cala, não tira dúvida, mas na hora de votar você vai com a maioria. ” Conselheiro-usuário6

Esse ambiente de incompreensão pode favorecer práticas clientelistas, manipulações e retirar do plenário do conselho sua autonomia, tornando-o vulnerável e comprometendo sua efetividade. O conhecimento específico na área da saúde não é e nem deve ser condição sine qua non para o desenvolvimento de deliberações legítimas e adequadas à sociedade. $\mathrm{O}$ conhecimento de "causa" dos usuários deve, não somente ser valorizado, como também, considerado quando se avalia a implantação/implementação de uma política pública de saúde, independente dos aspectos técnicos e científicos. Este é o fundamento legítimo que baseia teoricamente a existência dos conselhos plurais: uma decisão tecnicamente correta não é, necessariamente, a mais legítima socialmente ou até a mais adequada moralmente.

Salientamos ainda que não podemos afirmar que os pressupostos e os conhecimentos científicos não são importantes na tomada de decisões e na organização das ações. O que defendemos é que: apenas a validade científica não é suficiente para legitimar as decisões e ações, e que o sentimento de dever ultrapassa os limites daquilo que é exequível do ponto de vista científico (Batagelo, Benevides e Portillo, 2011). Autores (Bispo-Junior e Serapioni, 2021; Bispo-Junior e Gerschman, 2013) falam da tecnocracia, que preconiza que os convocados a decidir são apenas os poucos detentores de conhecimentos técnicos específicos. Excluindo do processo de tomada de decisão os cidadãos. Giddens (1991) defende que uma das características da modernidade é que estamos envoltos em "sistemas peritos", definidos como: "Sistemas de excelência técnica ou competência profissional que organizam grandes áreas dos ambientes material e social em que vivemos hoje. [...] Os sistemas nos quais está integrado o conhecimento dos peritos influencia muitos aspectos do que fazemos de uma maneira contínua.” (pg. 35).

Os entrevistados informaram que o assunto que apresentavam mais dificuldades relacionava-se à prestação de contas apresentada ao conselho trimestralmente: 
"Eu tenho dificuldades, por exemplo, com relação a recursos. Tem coisas assim, que a gente deixa um pouco a desejar, por que a gente não tem uma formação nessa área mais financeira, e ai às vezes a gente fica meio..." Conselheirousuário6.

Na realidade, aqui, a gente tinha que ter uma assessoria contábil, o conselho tinha que ter uma assessoria jurídica, tem coisa aqui, que eu digo: 'meu, Deus eu vou aprovar', por que se eu não aprovar vai é piorar para a população. Eu não entendo nada aqui, como é que eu vou dominar aquela prestação de contas? Que tem hora que a gente olha e não entende é nada[...] Conselheiro-usuário 1.

Ficou evidente a debilidade da análise da prestação de contas, e que, os conselheiros, alguns até membros da comissão que a analisa, não se sentem capacitados para tal função, deixando transparecer a vulnerabilidade desta atividade. Apesar de ser uma das principais funções deste órgão, fiscalizar as contas públicas.

Há também a questão pedagógica que foi apontada por alguns entrevistados:

"É tem um outro lado também na participação, é que forma a pessoa, é uma escola, para mim. É participando desse processo que vai adquirindo experiência, amadurecendo, né, e esse conhecimento, eu acredito que não vai acabar." Conselheiro-usuário3

É necessário fortalecer o papel dos conselhos de saúde com elaboração de políticas educacionais, para isso, há a necessidade de alocação de recursos financeiros para aumentar o acesso e participação, e que essas iniciativas fortaleceriam o controle social no Sistema Único de Saúde. Deve haver uma agenda de educação permanente para que os conselheiros possam participar ativamente das discussões e deliberações, e, que, sem isso, ocorre o comprometimento da eficácia do monitoramento e deliberação dos conselhos sobre política de saúde pública (Silva, Novais, e Zuchi, 2020).

\section{3) Relações de poder}

Em relação à percepção de relações de poder dentro do conselho, esta se revelou bastante divergente entre os entrevistados. A maioria relatou que não percebia tentativas de coerção ou qualquer outro tipo de influência que fosse resultante de força de cargo, ou algo semelhante. Alguns dos entrevistados que manifestaram ter essas percepções viam tais relações como algo natural, e que está presente em todas as instâncias de negociações. O fato que surpreendeu foi que quem teve essa postura de reconhecer que existiam, relações de poder dentro do conselho, foram os próprios representantes dos profissionais de saúde e até mesmo os membros da gestão. Outro aspecto importante foi que até entre os que revelaram em entrevistas percepção de algum poder de influência divergiam entre si. Alguns informaram que a gestão exercia algum poder coercitivo e manipulador, outros afirmaram que esta influência era por força do convencimento, através da argumentação apresentada, já que a gestão sempre se apresentava bastante embasada ao expor projetos e propostas. Observou-se que nem todos tinham esse olhar crítico, devido ao ambiente amistoso do plenário do conselho. Essa aparente cordialidade mascarava qualquer tentativa de manipulação do plenário, já que esta se apresentava de modo bem sutil, e, nem todos tinham essa percepção. Cabe nesta discussão, a reflexão sobre o "homem cordial", feita por Holanda (1995):

“[...] daremos ao mundo o 'homem cordial'. A ilhaneza no trato, a hospitalidade, a generosidade [...] representam, com efeito um traço definido do caráter brasileiro[...]. Seria engano supor que essas virtudes possam significar 'boas maneiras', civilidade. São antes de tudo, expressões legítimas de um fundo emotivo extremamente rico e transbordante. Na civilidade há qualquer coisa de coercitivo- ela pode exprimir-se em mandamentos e em sentenças.” (p. 146) 
A cordialidade imperava no ambiente do conselho, tornava assim, indelicada ou até mesmo antipática, uma manifestação contrária ao que estava sendo exposto em um clima tão "harmonioso". Conforme alguns relatos:

"Eu vou te ser sincera, que como tudo no Brasil, acaba que os mais poderosos estão ali, sempre influenciam [...] A opinião da secretaria, o que a secretaria acha que é mais correto, acaba tendo um valor maior, e acaba sendo obedecido, de certa forma [...] Infelizmente, poderia ser a voz da comunidade, dos usuários, e até a gente da categoria que estamos ali para isso, ser um pouquinho mais responsáveis, autônomos." Conselheiro-trabalhador1

"Acho que é uma arena sim, um espaço de disputa, tem que ser reconhecido e entendido como tal, não será diferente, é bom que seja assim, mas é bom também que o resultado disso tudo seja bom para a sociedade". Conselheiro-gestor2.

Como observado, dentre os que reconhecem que existem relações de poder, alguns enxergam como algo inerente ao processo de negociação, poucos foram os que realmente veem como força coercitiva. Quanto a essa questão, a literatura aponta várias situações em que se reconhece a relação assimétrica de poder e posição desfavorável do segmento usuário, com relação à gestão, no compartilhamento de poder de tomada de decisão (Krüger e Serapioni, 2020; Martinez e Kohler, 2016, Kohler e Martinez, 2015).

Outra forma de manifestação de poder identificada pelos entrevistados foi o conhecimento, ou seja, a argumentação apresentada que tinha êxito em aprovação pelo plenário, não pela imposição, mas pelo convencimento em dados. Esta foi a forma mais relatada pelos conselheiros, a defesa de argumentos da gestão, a força do convencimento.

"[...] na prática, quando você tem uma fala, uma propriedade naquilo que você fala, você consegue convencer mais pessoas disso e acaba gerando esse poder. E ai no conselho, quem se comporta dessa forma, que tem esse perfil, acaba se destacando mais, no caso, tem mais poder pelo que ele fala e pelo poder de convencimento dele, não digo pela formação ou função." Conselheiro-usuário3.

Conforme apontado por Habermas (1996), a estrutura da esfera pública reflete inevitavelmente assimetrias na disponibilidade da informação que é de chances desiguais para ter acesso à geração, validação, formação e apresentação de mensagens. Além dessas restrições sistêmicas, há a acidental desigualdade na distribuição de habilidades individuais. Os recursos para participar na comunicação política são no geral estritamente limitados.

\section{4) Efetivação das decisões}

Quanto aos resultados das deliberações do conselho, os entrevistados afirmaram que não tinham conhecimento do que acontecia com os projetos e propostas aprovados naquela instância de negociação, conforme os relatos:

"Tipo assim, se tem uma fiscalização, né? Ai, eu não sei te dizer. Às vezes você só delibera, só define os projetos e podem ser engavetados e não sair dali, eu ainda não vi se falando: 'vamos lá ver se estar saindo', né? Conselheiroprestador1

"Apesar de que o conselho não tem fiscalizado também, os conselheiros têm falhado um pouco". Conselheirotrabalhador2

Foram apontados, por alguns entrevistados, os entraves para a fiscalização das realizações das deliberações, há a necessidade de uma atuação mais efetiva dos conselheiros, enquanto agentes representantes da sociedade no papel de fiscalizador 
de política pública, no caso, a saúde. Essa atividade ultrapassa o papel do conselheiro, para se manifestar como ação de cidadania. Deve haver, também, cobrança de atos do poder público que efetivem as decisões que são legitimadas por um fórum colegiado. Sem essas ações, a credibilidade deste fórum pode ser comprometida. Esta problemática deve ser discutida, inclusive no plenário do conselho, dada a sua grande relevância para o funcionamento do mesmo. Neste conselho em estudo, não havia nenhum dispositivo legal que obrigasse o gestor a cumprir as deliberações do conselho.

Outro aspecto importante, diz respeito ao crédito ou consequentemente descrédito da participação. Pois, se, os partícipes não podem ver os resultados de suas deliberações, podem facilmente se desmotivarem e se desestimularem a se envolver em fóruns como estes.

\section{Considerações Finais}

A sociedade brasileira tem enfrentado uma série de obstáculos à efetivação dos conselhos de políticas públicas, destacando-se nesse contexto a baixa cultura associativa e reivindicativa. Este tem sido apontado como um dos mais importantes entraves de acesso ao processo de tomada de decisão à sociedade. Uma vez que a sociedade tem dificuldade em se organizar, para poder ser empoderada e reivindicar a efetivação de direitos assegurados constitucionalmente, esta se torna vulnerável e sujeita a uma gestão não permeável em dar atenção às necessidades da população.

Outra questão chave percebida nos resultados desta pesquisa, a qual pode se tornar impeditiva de uma participação eficaz da sociedade civil, é a posição dos governos e dos gestores responsáveis pela prestação dos serviços. Se estes se portarem de forma desfavorável à participação, podem comprometer todo o processo, desde o esvaziamento de poder dos conselhos, às práticas de cooptação e clientelismo, fazendo com que o órgão apenas homologue decisões tomadas em outras instâncias. Destaca-se, portanto, a necessidade de investimento em ações de educação permanente junto a gestores públicos e organizações da sociedade civil no tocante à relevancia e atributos do exercício do controle social no âmbito da saúde pública Brasileira. Além disso, a transparência e difusão de informações sobre o trabalho dos conselhos e seus partícipes pode favorecer esse processo. Estudos que analisem essas e outras estratégias, bem como a experiência de outros conselhos de saúde considerados casos bem sucedidos de exercício de controle social, podem, adicionalmente, favorecer a compreensão sobre o tema e elaboração de propostas de aprimoramento nesse campo.

Neste sentido, se por um lado a gestão necessita reconhecer e respeitar a função do conselho, por outro lado existe a necessidade de melhor preparo e organização da sociedade civil ao representar de fato os interesses do segmento dos usuários. Se cada uma destas partes expressar maior consciência de sua responsabilidade e papel, poderemos observar o desenvolvimento de intervenções apropriadas na formulação e acompanhamento de políticas públicas de saúde que influenciam a vida da sociedade Brasileira.

\section{Referências}

Almeida, D. R. (2010). Metamorfose da representação política [...]. In: Avritzer, L. (org.). A dinâmica da participação local no Brasil. Cortez. Batagelo, R., Benevides, L., \& Portillo, J. A. C. (2011). Conselhos de Saúde: controle social e moralidade. Saúde e Sociedade, 20 (3), 625-634.

Bispo-Junior, J. P., \& Gerschman, S. (2013). Potencial participativo e função deliberativa: um debate sobre a ampliação da democracia por meio dos conselhos de saúde. Ciência \& Saúde Coletiva, 18 (1), 7-16.

Bispo Junior, J. P., \& Serapioni, M. (2021). Community participation: Lessons and challenges of the 30 years of health councils in Brazil. Journal of Global Health, 11, 03061.

Chizzotti, A. (2005). Pesquisa em ciências humanas e sociais. (7a ed.), Cortez.

Cotta, R. M. M., Cazal, M. M., \& Martins, P.C. (2010). Conselho municipal de saúde: (re) pensando a lacuna [...]. Ciência e Saúde Coletiva, 15 (5), $2437-2445$. Giddens, A. (1991). As consequências da modernidade. Tradução de Raul Fiker. Unesp. 
Gil, A. C. (2019). Métodos e técnicas de pesquisa social. (7a ed.), Atlas.

Habermas, J. (1996) Between facts and norms: contribuitions to a discourse theory of law and democracy. Translations by Willian Rehg. Massachusetts Institute of Tecnology. Cambridge, MA: The MIT Press.

Holanda, S. B. (1995). Raízes do Brasil. (26a ed.), Companhia das Letras.

Klein, E. P. (2010). As relações intergovernamentais na implantação da política de saúde no estado do Acre de 1990 até 2008 [Tese]. Faculdade de Saúde Pública, Universidade de São Paulo.

Kohler, J. C., \& Martinez, M. G. (2015). Participatory health councils and good governance: healthy democracy in Brazil? International Journal for Equity in Health, 14 (21), 1-9.

Krüger, T. R., \& Serapioni, M. (2020). A participação nos sistemas de saúde de Brasil e Portugal: potencialidades e desafios. Revista Sociedade e Estado, 35 (1) $231-258$.

Martinez, M. G., \& Kohler, J. C. (2016). Civil society participation in the health system: the case of Brazil's Health Councils. Globalization and Health, 12 (64), $1-12$.

Pateman, C. (2012). Participatory democracy revisited. Perspective on Politics, 10 (01), 7-19.

Sader, E. (2002). Para outras democracias. In: Santos, B. S. (org.). Democratizar a democracia: os caminhos da democracia participativa. Rio de Janeiro: Civilização Brasileira.

Santos, B. S., \& Avritzer, L. (2002). Para ampliar o cânone democrático. In: Santos, B. S. (org.). Democratizar a democracia: os caminhos da democracia participativa. Rio de Janeiro: Civilização Brasileira.

Santos, B. S. (2002). Movimentos e aspirações democráticas. In: Santos, B. S. (org.). Democratizar a democracia: os caminhos da democracia participativa. Rio de Janeiro: Civilização Brasileira.

Serapioni, M., \& Matos, A. R. (2013). Participação em saúde: entre limites e desafios, rumos e estratégias. Revista Portuguesa de Saúde Pública, 31 (1), 11-22.

Silva, R. C. C., Novais, M. P., \& Zuchi, P. (2020). Permanent education as an inalienable responsibility of health councils: the current scenario in the Unified Health System. Clinics, 75, 1443, 1-6.

Turato, E. R. (2008). Construindo uma nova e particular metodologia qualitativa a partir do casamento de métodos modelares. In: Tratado da metodologia da pesquisa clínico-qualitativa. (3a ed.), Vozes. 